\title{
Planning Care for Neurology and Neurosurgery Patients with Critical IIlnesses
}

Most Canadian hospitals do not have special care units for patients with life-threatening diseases of the nervous system (see Table 1), variably called neurocritical or neuro-intensive care units. In these hospitals there are usually two levels of care: 1. the general intensive care unit (ICU) for patients who require endotracheal intubation and assisted ventilation and 2. the ward for all others

There are problems with the level and quality of care available for acutely ill neurological and neurosurgical patients, both within and outside gencral ICUs. General ICUs have broad case mixes and are rarely staffed by neurologically-trained nurses. The intensivist, surgeon, internist or anesthetist in charge may not be neurologically sophisticated. On neurology or neurosurgery wards, the nurse-to-patient ratio is often inadequate for patients with acute, life-threatening illnesses who do not qualify for an ICU bed. Special monitoring devices (c.g., for continuous electrocardiograms, oxygen saturation or intracranial pressure) are cither not available or nurses are not trained in their use. It is unlikely that the needs of such acutely ill patients are consistently met.

Table 1. Conditions Appropriate for Admission to a Neurocritical Care Unit.

1. Intracranial hemorrhage of any type including subarachnoid hemorrhage

2. Subdural hematoma

3. Epidural hematoma

4. Head injury: severe or moderate without a mass lesion

5 Spinal cord injury, inflammation or compression

6 Status epilepticus or frequent epileptic seizures

8. Myasthenia gravis with pharyngeal weakness or respiratory failure

9. Guillain-Barré syndrome with respiratory compromise or cardio vascular dysautonomia

10. Intractanial abscess with decompensation or seizures

11. Bacterial, fungal or tuberculous meningitis (after clearance from Infectious Diseases) or encephalitis

12. Intracranial tumors and decompensation or frequent seizures

13. Malignant hypothermia or malignant neuroleptic syndrome

14. Ischemic stroke with brain swelling of "progressing" or unstable stroke; stroke with compromisc of upper airway function.

Modified with permission from Ropper $A H$ and Annals of Neurolog. ${ }^{24}$
Quality cate for such patients is possible if we plan for comprehensive management of various acute illnesses with care maps or critical paths in which care is co-ordinated among providers. ${ }^{1.2}$ Managed care is a method of organizing care that emphasizes communication and coordination among doctors and nurses. ${ }^{3}$ An interdisciplinary approach is used in decisionmaking for patients with various illnesses. In the acute phase this is a daily plan with projected outcomes. This information is incorporated into critical paths or care maps. Critical paths describe planned interventions and activities over time. ${ }^{+}$Care maps do this and, in addition, describe indicators for measuring quality and have outcome indices suitable for continued improvement initiatives.

\section{Levels of Enhanced Carc}

Intensive Care Units have been divided into 3 "levels".

Level 111: The physician director or qualified designate is in the unit at all times. There is a high (usually 1:1) nurse10-patient ratio. Such units are in academic centres with active teaching and research.

Level II: A full or part-time director is in the hospital at all times. There is a high to intermediate nurse-to-patient ratio.

Level I: There is a part time director. Immediate care is dependent on other in-house physicians. There is a lower nurse-to-patient ratio.

All hospitals with Level III units should also have Level I and $I I$ units to provide appropriate levels of care. Intermediate care units (Levels I and II), also known as "step-down units", provide treatment for patients who do not require assisted ventilation in a designated ICU, but who require more than ordinary ward management.?

When we reviewed the medical records of the most common potentially life-threatening illnesses affecting the nervous system, we found that an intermediate care unit would be appropriate for over half of the cases in need of more than ordinary ward care (see Table 2). Cases considered appropriate for intermediate

Reprint requess to: D. G. B. Young, Depanment of Clinical Neurological Sciences. Victoria Hospital, 375 South Street, London, Ontario. Canada N64 465 
care were those with all of the following characteristics: (a) serious but potentially reversible neurological impairment, (b) no requirement for assisted ventilation or endotracheal intubation and (c) a need for continuous observation or monitoring. These included conditions with continuously or intermittently impaired consciousness, frequent seizures, weak respiratory muscles, or profound limb weakness.

\section{Managed Care: Process vs. Structure}

There is mounting evidence that the process by which care is delivered is more important than the physical unit in which the care is delivered. This applies to general intensive care and to at least some aspects of neurointensive care.

A prospective study by Knaus and colleagues involved 5,030 patients in general intensive care units in 13 American tertiary care hospitals. ${ }^{8}$ Cases were carefully stratified and outcomes were compared for matched patients. Hospitals varied significantly in mortality rates. It was found that the differences in outcomes related to the interaction and coordination of the ICU staff, rather than to the administrative structure of the unit, the types of specialized treatment or the teaching status of the hospital.

Indredavik and colleagues conducted a more focused study on stroke units." They randomly assigned 220 patients with acute strokes into either a stroke unit or on a general medical ward. The stroke unit used established investigative and management protocols; a team approach involved physicians, nurses, rehabilitation and family members. Rehabilitation began directly after admission. The following statistically significant differences favored the stroke unit patients: lower early mortality, a higher percentage living at home and a lower percentage of patients who were chronically institutionalized, Other randomized studies have shown that patients treated in stroke units have significantly lower mortality at 17 weeks and I year from admission than patients not so admitted. ${ }^{10.11}$ A recent meta-anal$y$ sis of 10 randomized trials used a broad definition of stroke units, including management in discrete units as well as wards with mobile stroke teams. ${ }^{12}$ Cases with such managed care had $28 \%$ lower early and $21 \%$ lower late mortality than did patients not managed in this fashion.

In contrast to the above, a Canadian study ${ }^{13}$ failed to show the benefis of a stroke unit, but in their hospital a team of stroke specialists consulted on patients throughout the hospital. The results again demonstrated that outcome depends more on the comprehensive nature of care rather than on the particular structure or setting in which it is delivered.

Managed care for other conditions other than stroke also show improved outcomes. A retrospective study by Wärme and co-workers ${ }^{14}$ demonstrated that the introduction of a neurosurgical ICU was associated with an increase in "good recoveries" for matched patients, from 15 to $52 \%$; this was most impressive for those with Glasgow Coma motor scores of $\geq 4$. Although these units were not "intermediate" because most patients were ventilated, they provided well organized, continuous care with well-trained staff using established methods of surveillance and treatment.

Reduced costs with improved resource utilization are welcome products of managed care. A randomized controlled trial showed that a medical team coordinator significantly reduced the length of stay in a Canadian teaching hospital. ${ }^{15}$ In addition. patients in the managed care setting had a higher level of satisfaction than did the control group.

Table 2. A Survey of Cases Suitable for a Neurocritical Care Unit

\begin{tabular}{|c|c|c|c|}
\hline Diagnosis & $\begin{array}{l}\text { \# Cases/year } \\
\text { (No, with assisted } \\
\text { ventilation) }\end{array}$ & $\begin{array}{l}\text { Percentage } \\
\text { Requiring } \\
\text { NCCU }\end{array}$ & $\begin{array}{l}\text { Ave. } \# \text { NCCU } \\
\text { Cases/yr }\end{array}$ \\
\hline Head injury & $200(44)$ & 62.5 & 125 \\
\hline Ischemic stroke & $173(52)$ & 75 & 130 \\
\hline \multicolumn{4}{|l|}{ Intracranial } \\
\hline hemorrhage & $77(52)$ & 100 & 77 \\
\hline Status epilepticus & $10(6)$ & 100 & 10 \\
\hline \multicolumn{4}{|l|}{ Guillain-Barré } \\
\hline syndrome & $14(6)$ & 57 & 8 \\
\hline \multicolumn{4}{|l|}{ Alcohol } \\
\hline withdrawal & $24(0)$ & 21 & 5 \\
\hline Encephalitis & $3(1)$ & 67 & 2 \\
\hline Total & $\begin{array}{l}501 \\
(161=32 \%)\end{array}$ & $357 / 501=71 \%$ & $* 357$ \\
\hline
\end{tabular}

Legend: est. $=$ estimated number; $\mathrm{NCCU}=$ Neurocritical Care Unit (includes those who require ventilation or intermediate care); $y r=$ year

* From this sample of 501 cases, $32 \%$ (161 cases) required endotracheal intubation and ventilation. This leaves $357-161=196$ patients/yr who are suitable for an intermediary unit, but for whom a ward bed is inadequate.

(From a Needs Analysis by K. Elisevich and B. Young

Using HMRI data and a Sampled Chart Review for Victoria Hospital, London, Ontario:

Pooled Data from 1988-1992) 


\section{Improving Care in Existing General ICUs}

The general ICU requires more involyement by neurologists, neurosurgeons and neuro-nurses in the planning of patient care. Increased neurological and neurosurgical training of ICU nurses is needed. The creation of "special" neuro-beds for monitoring should be considered. An improved spirit of co-operation and collaboration should replace previous "turfdoms".

\section{Provision of Intermediate Care}

Providing intermediate care on the ward requires careful planning, co-operation and the establishment of open lines of communication within and between the medical and nursing staff. ${ }^{16}$

Most institutions will need to use existing structures and resources. For example, if a hospital has a team of trained neuro-intensivists, neurological-neurosurgical special care units could be "stand-alone" entities. In other hospitals, there will need to be more interaction of clinical neuroscientists with intensivists, respiratory physicians, anesthetists, microbiologists, etc., to provide optimal care. This could be within identified physical units (intermediate care or step-down units) or as an interdisciplinary team that identifies patients and provides care maps for them within existing wards.

Criteria for admission to and discharge from intermediate care need to be established. The medical director and charge nurse must play key roles in the co-ordination of patient transfers. Care maps should be developed for problems that are high risk, high volume and problem prone. ${ }^{17}$

The medical director, or physician primarily responsible for intermediate care, must be clearly identified. This individual and/or his designate or co-physicians must make regular rounds with the nursing team. Availability of an identified physician at all times should be assured. If one physician serves as the "permanent" director, other physicians must be designated for those times when he/she is unable to be on duty. A rotating directorship may also be used.

Similarly, a head or charge nurse for intermediate care should be appointed. The primary nursing model is the most satisfactory model for intermediate care: the nurse plans comprehensive nursing care for a limited number of patients whom she/he knows well. ${ }^{18}$

If the intermediate care unit is organizationally separated from other ward activities, the unit may have its own nursing staff. More commonly the nurses from the ward rotate through the unit. Either arrangement requires careful planning to meet the needs and expectations of the staff.

Planning for the caseload requires good historical data, including numbers of patients with various diseases along with levels of patient care or workload measurement tools (e.g., Medicus, GRASP, Project Research in Nursing or the Therapeutic Intervention Scoring System) and length of stay data. ${ }^{19,20}$ Ideally this is computerized in a modelling system. ${ }^{21}$ Data on neurological and neurosurgical cases from the intensive care unit should be transferred to the intermediate care unit, just before the patient is moved.

Essential educational programs for more intensive neuronursing are established in various centres through the Certification Program for the Canadian Association of
Neuroscience Nurses. The Canadian Nurses Association has designated neuroscience nursing as a specialty; certification examinations and educational upgrades are available. These provide essential knowledge for the theoretical understanding as well as practical management of the neurological, general medical and psychological aspects of care. There should also be a program of continuing education for all nurses involved in intermediate care. This should take the form of weekly staff conferences, regular lectures, interdisciplinary conferences, attendance at rounds and special seminars.

Ideally, there should be multidisciplinary programs/projects that involve both nursing and medicine for quality improvement. ${ }^{22}$ This can join with utilization management to document efficiency and effectiveness.

There may be higher stress. level among nurses and clinicians during the start-up of the unit. ${ }^{16}$ However, this should subside quickly and a greater level of satisfaction should develop as the operation of the unit improves. ${ }^{23}$

\section{Justification}

The challenges are to demonstrate improved clinical outcomes and economic benefits (e.g., in-hospital costs, lengths of stay and the need for long-term institutionalization) of such planned management for acutely ill neurological and neurosurgical patients. This may require "demonstration projects" that show the effectiveness of intermediate care units, along with supportive technology, in such economically stressed times. There are several arguments for considering the implementation of managed care for critical illnesses of the nervous system at this time:

1. Feasibility: We now admit fewer patients and lengths of stay should be shorter with better discharge planning. The number of ward beds could then be reduced. If nearly the same nursing complement is maintained, the nurse-to-patient ratio would increase, allowing for a higher level of managed care on the ward (either in a "unit" or throughout the ward, e.g., with higher weighting to certain patients).

2. Cost- and resource-saving advantages for hospitals: the number of patient-days in the ICU may be reduced if managed care is utilized in the ICU and if intermediate care is available outside the ICU; overall length of hospital stay should be reduced with case management and better discharge planning.

3. If more patients return home (as has been shown for stroke units and neurosurgical units for head injuries), the overall societal burden will be less.

4. There are a number of benefits to morale and efficiency: better communication between nurses and physicians; stronger liaison of medical and nursing management; increased use of nursing skills and knowledge with increased sense of autonomy, job satisfaction and self-fulfillment.

\section{Conclusion}

We should reorganize the care in all our in-patient units: there is a higher acuity of illness among in-patients; critically ill patients may not be consistently receiving optimum care and resources are not being efficiently utilized. Clinical neuroscientists should be proactive in providing improved care at a time of increasingly restricted funding. Since we are on the "front lines" 
of care, we have the best perspective on what needs to be done in assigning priorities. A medical-nursing interdisciplinary team approach with the principle of doing what is best for the patient is the most appropriate paradigm. An enhanced care delivery model should provide improved outcomes and better use of resources.

\section{G. Bryan Young and Diane Thrasher London, Ontario}

\section{Acknowledgements}

The authors wish to thank Dr. Charles Bolton, Dr. Richard Moulton, Dr. Allan Ropper and Heather Ryan, MSN for helplul advice.

\section{References}

1. Health Services Research Group. Quality of Care: 1. What is quality and how can it be measured? Can Med Assoc.J 1992; 146:21532158.

2. Health Services Research Group. Quality of Care: 2. Quality of care studies and their consequences. Can Med Assoc J 1992; 147: 163167 .

3. Mosher C. Cronk P. Kidd A, et al. Upgrading practice with critical pathways. Am J Nurs 1992; $92: 41-44$

4. Zander K. Care maps; the core of cost/quality care. The New Definition 1991: 6:1-3.

5. Zander K. Quantifying, managing and improving quality: I. How care maps link CQI to the patient. The New Definition 1992; 7: 1-3.

6. Minarda DR. Williams $A$. Loirat Ph. (eds) Management of Intensive Care: Guidelines for Better Resource Use. Kluver Academic Press 1990.

7. Popovicj, John Ir. Incermediate care units: graded care options. Chest 1991; 99:4-5.

8. Knaus WA. Draper EA, Wagner DP, Zimmerman JE. An evaluation of outcome from intensive care in major medical centres. Ann Intern Med 1986: 104: 410-418.
9. Indredavik B. Bakke F. Solberg. el al. Benefit of a stroke unit: a randomized clinical trial. Stroke 1991; 22: 1026-1031.

10. Garraway WM, Akhtar AJ, Hockey L, Prescott RJ. Management of acute stroke in the elderly: preliminary results of a controlled trial. Br Med J 1980; 281:827-829.

11. Strand T. Asplund K, Eriksson S, et al. A non-intensive stroke unit reduces functional disability and the need for long-term hospitalization. Stroke 1985; 16: 29-34.

12. Langhorne P, Williams BO, Gilchrist W, Howe K. Do stroke units save lives? Lancet 1993: 342: 395-398.

13. Wood-Dauphinee $S$, Shapiro S, Bass ER, et al. A randomized trial of team care following stroke. Stroke 1984; $15: 864-872$.

14. Wärme P-E, Bergström R. Persson L. Neurosurgical intensive care improves outcome after severe head injury. Acta Neurochurgica 1991; 110: 57.64

15. Moher D, Weinberg A, Hanlon R, Runnalls K. Effects of a medical team coordinator on length of hospital stay. Can Med Assoc J 1992; 146: $511-515$.

16. Macintyre ML, Shay S-B. Creating a step-down unit. Dimensions in Health Care 1989; 66: 24-27.

17. Pike AW, McHugh M, Canney KC, et al. A new architecture for quality assurance: nurse-physician collaboration. J Nurs Care Qual 1993; 7:1.8.

18. Clark EL. A model: nurse staffing for effective patient care. J Nursing Administration 1977; 7: 22-27.

19. O'Brien-Pallas L, Leat P, Deber R. Till J. A comparison of workload estimates. CJNA 1989;2: 16-23.

20. Cullen DJ, Civetta JM, Briggs BA, Ferrara LC. Therapeutic Intervention Scoring System: a method for quantitative Comparison of Patient Care. Criti Care Med 1974; 2: 57-60.

21. Zilm F, Brown ML. Evaluating ICU beds and the use of step-down units. Healthcare Financial Management. 1984; 38: 26-34.

22. Clifford J, Horvath K. Advancing Professional Nursing Practice. New York: Springer 1990.

23. Wood RG, Bailey NO. Tilkemeier D. Managed care: the missing link in quality improvement. J Nurs Care Qual 1992; 6: 55-65.

24. Ropper AH. Neurological Intensive Care. Ann Neurol 1992; 32 . 564.569 . 